\title{
Coexistence of Bronchiectasis and Rheumatoid Arthritis: Revisited
}

\author{
Maria M Wilczynska MRCP, Alison M Condliffe PhD FRCP, and Damian J McKeon PhD FRCP
}

\author{
Introduction \\ Limitations \\ Epidemiology \\ Etiology \\ Risk Factors \\ Smoking \\ Infections \\ Pulmonary Function Testing \\ Imaging \\ Prognosis \\ DMARDs and Infection Risk \\ Management \\ Summary
}

\begin{abstract}
The presence of bronchiectasis (BR) in patients with rheumatoid arthritis (RA) has been recognized for many decades; nevertheless, little research has been undertaken in this area. It is important to recognize that BR coexistent with $R A$ differs from the other types of BR. The purpose of this descriptive review was to delineate the epidemiology, etiology, risk factors, pulmonary function testing, imaging, prognosis and management of concomitant BR and RA. To inform our study we searched the PubMed, EMBASE, CINAHL, and MEDLINE databases, using combinations of the following key words: computed tomography, lung function tests, rheumatoid arthritis, bronchiectasis, biological agents, and interstitial lung disease. The number of published papers covering this topic is limited, but several relevant conclusions can be drawn. Patients with concomitant RA and BR have worse obstructive airways disease, increased susceptibility to recurrent pulmonary infections, faster lung function decline, and higher mortality, compared with subjects with either RA or BR alone. The use of disease-modifying anti-rheumatic drugs (both biological and non-biological) for RA in RA-BR patients imparts a further challenge in managing these patients. Although there are not any published guidelines on the management of coexisting RA-BR, we have attempted to provide such recommendations, based on the literature review and our experience. Key words: rheumatoid arthritis, bronchiectasis. [Respir Care 2013;58(4):694-701. (C) 2013 Daedalus Enterprises]
\end{abstract}

\section{Introduction}

Rheumatoid arthritis (RA) is a chronic, progressive inflammatory disease, with a prevalence of $1 \%$ across the

\footnotetext{
Dr Wilczynska is affiliated with the Respiratory Medicine Department, Prince Philip Hospital, Llanelli, United Kingdom. Dr Condliffe is affiliated with the Respiratory Medicine Division, Department of Medicine, Addenbrooke's Hospital, Hills Road, Cambridge, United Kingdom. Dr McKeon is affiliated with the Respiratory Medicine Department, Ysbyty Gwynedd, Penrhosgarnedd, Bangor, United Kingdom.
}

general population. ${ }^{1}$ It has a strong association with a variety of pulmonary conditions, including pulmonary fibro-

\footnotetext{
The authors have disclosed no conflicts of interest.

Correspondence: Maria M Wilczynska MRCP MBBS, Respiratory Medicine, Prince Philip Hospital, Bryngwyn Mawr, Dafan, Llanelli, SA14 8QF United Kingdom. E-mail: mwilczynska@doctors.org.uk.
}

DOI: $10.4187 /$ respcare. 01857 
sis, lung nodules, bronchiolitis, tuberculosis, pleural effusions, and bronchiectasis (BR). ${ }^{2,3}$ An association between RA and BR has been recognized for many years, with the first studies published in the early 1960s. ${ }^{4}$ We present a literature review that explores the epidemiology, etiology, risk factors, pulmonary function test, imaging, prognosis, and management of these 2 conditions in conjunction. The objective of this study was to synthesize available literature for concurrent RA-BR. Other RA-associated pulmonary disease will not be covered in this review. Our secondary aim was to formulate recommendations for the management of this patient group.

The searched databases included PubMed, EMBASE, CINAHL, and MEDLINE. Searches were performed using combinations of the following key words: computed tomography, lung function tests, rheumatoid arthritis, bronchiectasis, biological agents, and interstitial lung disease. Only articles published in English and relevant to this review were included. The date of the last search was April 2012.

\section{Limitations}

The limited number of publications concerning BR in RA, and the broad methodological differences across the available studies precluded formal meta-analysis. Reviewed studies differ substantially in terms of the study population, including patient age and sex, use of nonbiological and biological disease-modifying anti-rheumatic drugs (DMARDs), duration of RA and BR, underlying pulmonary disease, and smoking status. Most of the studies were based on a small number of subjects.

The diagnostic criteria for RA and BR also varied between studies. In most recent papers, authors used the American Rheumatism Association 1987 revised criteria to identify patients with RA; however, in some earlier studies RA was diagnosed by clinical judgment alone. The criteria used to make the diagnosis of BR have also varied over the years, with early studies using clinical features and/or an abnormal chest radiograph to diagnose BR, while in later papers this diagnosis was supported by the use of high-resolution computed tomography (HRCT).

\section{Epidemiology}

The prevalence of BR has been described as 52.3 cases per 100,000 adults in the general population, ${ }^{5}$ although a recent study ${ }^{6}$ has suggested that this prevalence may be rising, perhaps reflecting better awareness of the condition and increased use of HRCT. The prevalence of BR in the RA population is estimated at $2-3.1 \%, 4,7$ although one study based on the post-mortem examination of patients with RA reported the occurrence of BR to be as high as $12 \% .{ }^{8}$ Conversely, the prevalence of RA in patients with BR is generally reported to be $3-5.2 \% .9,10$ However, McShane et al investigated causes of BR in the United States population and found that $28.6 \%$ of BR in African Americans was secondary to RA, perhaps reflecting the high incidence of RA in this group. ${ }^{11}$

\section{Etiology}

Several hypotheses have been put forward to explain the mechanisms underlying the development of BR in RA. Of note, RA usually precedes the development of BR (by 11.5-24.7 y). ${ }^{12,13}$ The development of BR does not influence or reflect RA severity. Disease activity and disability parameters, including the extent of arthritis, functional grading, and the occurrence of subcutaneous nodules, are similar in the 2 groups. The erythrocyte sedimentation rate tends to be higher in those with BR, but there were no other significant differences between the 2 groups, either hematologically or serologically. ${ }^{14-16}$

Demoruelle et al postulated a link between autoimmunity in RA and airway damage. These authors studied 3 groups of patients: subjects without inflammatory arthritis but with elevated anti-cyclic citrullinated peptide (CCP) antibodies, antibodies-negative controls, and subjects with early seropositive RA. There was a significant difference in the pulmonary involvement (principally airway thickening and bronchiectasis, confirmed by HRCT) between antibody positive group and controls: $76 \%$ versus $33 \%$, respectively. The antibodies-positive subjects without clinical features of RA had similar lung abnormalities to patients with early RA. Although, as stated above, the diagnosis of RA preceded that of BR in most cases, the researchers concluded that the lung may be an early site of autoimmune-related injury, and potentially a site of generation of RA-related autoimmunity. ${ }^{17}$

McMahon et al studied immunoglobulin (Ig) levels, autoantibodies, and complement levels in patients with RA-BR versus those with RA or BR alone, and detected no significant differences. Levels of complement C3, C4, $\mathrm{C} 1-\mathrm{INH}$, and $\mathrm{CH} 50$ did not differ between the groups, but lower levels of circulating immune complexes and acute phase reactants were found in patients with BR than in those with RA-BR. ${ }^{18}$ Taking these studies together, it would seem that RA-associated autoimmunity is not an important causative factor for BR.

Snowden et al postulated that defective stimulated antibody production might contribute to the propensity of patients with RA to develop BR; they found that 3 out of 20 patients RA-BR (vs none with either condition alone) had a defective $\operatorname{IgG} 2$ response to polysaccharide antigen (but normal responses to protein antigen); 2 of the 3 
patients were receiving gold therapy. ${ }^{19}$ Although these numbers are small, it should be noted that specific antibody production has been identified as a predisposing factor for $\mathrm{BR}^{9}$; hence, it is plausible to speculate that DMARDs for RA suppress the immune system and predispose to pulmonary infection and the development of BR.

Some researchers have postulated that concurrent RA-BR is due to a genetic predisposition conferring susceptibility to both conditions. Severe BR is the norm in cystic fibrosis, which is caused by the presence of homozygous or compound heterozygous defects in the cystic fibrosis transmembrane conductance regulator (CFTR) gene. Casals et al performed CFTR gene analysis in 55 adult patients with BR and found mutations in 20 patients (36\%); in 14 of the patients (25\%) only one mutant allele (in most cases the more functional M470 allele) was detected. ${ }^{20}$ They concluded that CFTR heterozygous mutations might contribute to the development of BR. It should be noted, however, that Pasteur et al did not find an excess of heterozygous CFTR mutations in their study of adult BR. ${ }^{10}$ Interestingly, in a study involving 26 patients with RA-BR, 4 (15.4\%) had a heterozygous delta F508 CFTR mutation, while no mutations were detected in 29 matched controls with BR alone and 29 with RA alone. Those with delta F508 mutation had more frequent chronic sinusitis, more severe pulmonary involvement, and lower values of nasal potential differences than patients with RA-BR without CFTR mutation. ${ }^{21}$ The frequency of CFTR mutations was higher in family members with RA-BR or BR alone than in unaffected relatives or healthy controls. This group has therefore proposed that the presence of CFTR mutations in patients with RA may be a marker of developing RA-associated BR. ${ }^{22}$ Additional studies would be of value to further investigate this hypothesis.

Only limited studies have been performed to evaluate the role of human leukocyte antigen (HLA) in the development of RA-BR. HLA variant DQB1*0601 was found to be increased in subjects with BR, with or without RA (but only significantly in RA-BR subjects). The DQB1*0301, DQB $1 * 0201$, and DQA $1 * 0501$ frequencies were also increased in the RA-BR group, as compared to those with RA alone. ${ }^{23}$ However, this finding was not confirmed in a study of unselected RA patients who underwent HRCT to evaluate lung disease. Those diagnosed with BR had a nonsignificant increase of HLA DR2 and DR7, but a significantly lower prevalence of the HLA DQA $1 * 501$ allele. ${ }^{15}$ Bilgici et al studied HLA DR4 and DR1 genotypes and, again, there were not any significant differences in their frequencies between the groups. ${ }^{24}$ The clinical importance of these findings is uncertain, as the studies included small numbers of subjects, and the results do not seem to be consistent.

\section{Risk Factors}

\section{Smoking}

Smoking increases the risk of RA. In a Swedish observational population study the authors suggested that smoking was responsible for $35 \%$ of anti-CCP antibody-positive RA cases. Increased risk of anti-CCP antibody-positive RA was shown to be associated with smoking in a dose response manner, particularly in the presence of HLADRB1 shared epitope alleles. 25 These findings were confirmed in a meta-analysis of 16 observational studies. Researchers found that in rheumatoid-factor-positive RA men, heavy smoking was a significant risk factor for RA: odds ratio $3.91,95 \%$ CI $2.78-5.50 .{ }^{26}$ Specific studies on the association of RA-BR with smoking are lacking, but in fact the limited data available suggest that patients with RA-BR are more likely to be non-smokers, compared to those with RA alone. ${ }^{15,27,28}$ Thus, from the available literature there is no evidence to implicate smoking in the association of RA and BR.

\section{Infections}

Respiratory tract infections are another factor with the potential to influence the association of RA-BR and disease outcomes. Severe and recurrent lower-respiratory-tract infections (particularly in childhood) have long been recognized to predispose to $\mathrm{BR}$, and this has been confirmed in more recent studies (eg, Pasteur et al). ${ }^{10} \mathrm{Au}$ et al reported that increased risk of infections is related to RA disease activity, independent of treatment with DMARDs, with more active disease associated with higher rate of all types of infections. ${ }^{29}$ Also, the presence of airways colonization in patients with RA-BR was reported to be associated with increased risk of infections $(2.5 \pm 1.7$ infections per patient-year). ${ }^{30}$ However, in the same study, the use of DMARDs was a more powerful predictor of lowerrespiratory-tract infection than airway colonization, consistent with other reports. Thus, the role of DMARDs in predisposing to recurrent pulmonary infection warrants further consideration (see below).

\section{Pulmonary Function Testing}

The physiology of the bronchiectatic lung in RA differs from non-rheumatoid-related bronchiectasis. Spirometry shows more pronounced obstructive airways disease with less reversibility in the RA-BR population than in the other types of BR. ${ }^{18,24}$ In subjects presenting with RA and small airways involvement (low forced expiratory flow during the middle half of the $\mathrm{FVC}$ maneuver $\left[\mathrm{FEF}_{25-75 \%}\right]$ ), $\mathrm{BR}$ is a common finding and occurs in $62-71 \%$ cases. ${ }^{15,31}$ However, small airways disease is also common in patients 
with RA alone, even in the absence of interstitial lung disease. ${ }^{32}$ The degree of bronchiectasis has been found to correlate with the forced expiratory ratio $\left(\mathrm{FEV}_{1} / \mathrm{FVC}\right)$, while the degree of bronchial wall thickening correlated with $\mathrm{FEF}_{25-75 \%}$. Bronchial dilatation in BR-RA was also independently associated with the decrease in FVC. ${ }^{33,34}$ There is evidence from another small study, by Goeminne et al, that a rise in RA disease activity score is associated with a decline of $\mathrm{FEV}_{1}$, and vice versa. ${ }^{35}$

In contrast to these findings, there are 2 small studies in which researchers reported that RA-BR lung was not associated with obstructive spirometry. In a study of 20 patients with RA, McDonagh et al documented restrictive spirometry; 4 of the patients had traction BR secondary to pulmonary fibrosis. ${ }^{36}$ In the second study, in a group of 20 non-smoking RA patients with no respiratory symptoms, 5 were diagnosed with BR by HRCT. There were no significant differences in spirometry between the patients with RA alone and RA-BR group. ${ }^{37}$ The small numbers and selected populations covered by these 2 studies make it difficult to draw conclusions related to RA-BR pulmonary physiology from them.

\section{Imaging}

Radiological investigations play a crucial role in the evaluation of RA-related lung disease. The introduction and now widespread availability of computed tomography, especially HRCT, has resulted in earlier identification of patients with BR (Figure). ${ }^{38}$

In HRCT studies of patients with RA, reports on the prevalence of BR in RA vary according to the inclusion criteria. Across studies, investigators have included or excluded patients depending on smoking status or the presence of respiratory symptoms. Other variables include mean age, mean duration of RA, and the presence of BR associated with or without pulmonary fibrosis. Given this variation, in a group of 10 studies in which the American College of Rheumatology 1987 revised criteria ${ }^{39}$ were used to diagnose RA, the overall incidence of RA-BR was 12$62 \%$ (Table). BR was an independent finding on HRCT requested for patients with suspected RA and interstitial lung disease in $30 \%$ of cases. ${ }^{36}$ In unselected RA populations the identification of BR on HRCT varied between $17-30.5 \%, 15,24,36,42,43$ with a prevalence of symptomatic $\mathrm{BR}$ of $2.9 \% .^{7}$ There is ethnic variation in the prevalence of $\mathrm{BR}$, as in Chinese patients with RA who underwent HRCT this condition was detected only in $3.64 \% .{ }^{11}$ Detection of bronchiectasis in lifelong non-smokers with RA was common, at 25-58\%. ${ }^{16,37,44}$ Patients with RA and normal chest radiographs had a prevalence of BR on HRCT reported as $13-30 \% .{ }^{31,43}$ In contrast, those with RA and chronic respiratory symptoms or abnormal chest radiographic findings had a higher rate of BR, with traction bronchiectasis

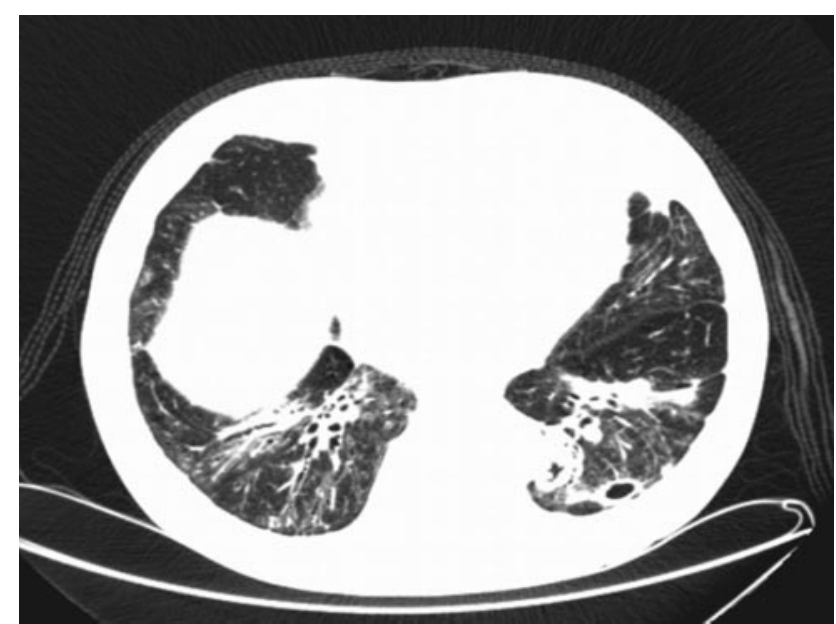

Figure. High-resolution computed tomography of the lungs in patient with rheumatoid arthritis. Bronchiectasis is evidenced by cylindrical dilatation of peripheral bronchi in the lower lobes, associated with bronchial wall thickening and retention of secretions.

being present in 51-75\% and non-traction bronchiectasis in $22-33 \% .{ }^{28,33,45} \mathrm{In}$ a prospective study of 46 unselected patients with RA undergoing HRCT, Despaux et al found that BR was the most common abnormality and was detected in $50 \%$ of the subjects, the majority of whom (18/ 23) had no antecedent respiratory symptoms. ${ }^{46}$

From these studies it is apparent that radiological evidence of $\mathrm{BR}$ is present in a high percentage of patients with $\mathrm{BR}$, even in the absence of respiratory symptoms. However, longitudinal studies are needed to evaluate the clinical importance of these findings.

\section{Prognosis}

It is important to recognize that RA-BR subjects have mortality 7.3 times higher than the general population, 5 times higher risk than the RA group alone, and 2.4 times higher risk than the BR group. ${ }^{47}$ In patients with RAassociated lung disease the 5-year survival rate was reported as $87.1 \%$ in the BR group, and only patients with RA and interstitial lung disease had a lower 5-year survival rate (36.6\%). ${ }^{48}$ Longitudinal studies of treatment interventions in these patients are urgently required.

\section{DMARDs and Infection Risk}

DMARDs are defined by their ability to slow disease progression. While there have been many studies of infection risk with these agents, few have dealt with respiratory infections alone, and almost none with the risk of respiratory infections in patients with structural lung disease. Since knowledge of the potential risk of infection will inform the management of patients with RA-BR, a review of this literature is presented below. 
Table. Bronchiectasis in Patients With Rheumatoid Arthritis

\begin{tabular}{|c|c|c|c|c|c|c|c|c|}
\hline First Author & Year & Study Type & $\begin{array}{c}\text { Subjects With } \\
\text { Rheumatoid } \\
\text { Arthritis } \\
n\end{array}$ & $\begin{array}{c}\text { Age } \\
\text { mean } \pm \mathrm{SD} \\
\text { (range) } \mathrm{y}^{*}\end{array}$ & $\begin{array}{c}\text { Duration of } \\
\text { Rheumatoid } \\
\text { Arthritis } \\
\text { mean } \pm \text { SD } \\
\text { (range) } y^{*}\end{array}$ & $\begin{array}{c}\text { Bronchiectasis } \\
\text { Confirmed } \\
\text { Via HRCT } \\
\text { no. }(\%)\end{array}$ & $\begin{array}{c}\text { Presence of } \\
\text { Respiratory } \\
\text { Symptoms } \\
\text { no. }\end{array}$ & $\begin{array}{c}\text { Non-smokers } \\
\text { no. }\end{array}$ \\
\hline McDonagh $^{36}$ & 1994 & Observational prospective & 40 & $66(41-79)$ & $9(1-27)$ & $10(25)$ & 20 & 32 \\
\hline Remy-Jardin ${ }^{28}$ & 1994 & Observational retrospective & 83 & $57 \pm 9(36-79)$ & $12 \pm 8(0.3-45)$ & $23(27)$ & ND & 76 \\
\hline Cortet $^{40}$ & 1995 & Observational retrospective & 77 & $57 \pm 10(36-79)$ & $12 \pm 8$ & $23(30)$ & 39 & 14 \\
\hline Hassan $^{37}$ & 1995 & Observational prospective & 20 & $59(44-72)$ & $9(1-30)$ & $5(25)$ & ND & 20 \\
\hline Cortet $^{15}$ & 1997 & Observational prospective & 68 & $58.8 \pm 10.6$ & $12 \pm 9.2$ & $18(26)$ & 47 & 52 \\
\hline Perez ${ }^{31}$ & 1998 & Observational prospective & 50 & $57.9 \pm 1.5(34-73)$ & $14.4 \pm 1.3(1-48)$ & $15(30)$ & ND & 40 \\
\hline Terasaki $^{34}$ & 2004 & Observational retrospective & 34 & $61(47-80)$ & $12(0-39)$ & $21(62)$ & 34 & 34 \\
\hline Bilgici $^{24}$ & 2005 & Observational prospective & 52 & $53.6 \pm 11.2$ & $8.37 \pm 8.17$ & $6(12)$ & 21 & 39 \\
\hline Metafratzi $^{16}$ & 2007 & Observational prospective & 43 & $56.5 \pm 12$ & $10.0 \pm 1.4$ months & $25(58)$ & ND & 43 \\
\hline $\mathrm{Zou}^{41}$ & 2010 & Observational retrospective & 110 & $55.4 \pm 13.8(24-84)$ & $8.25 \pm 9$ & $4(3.6)$ & 15 & 91 \\
\hline \multicolumn{9}{|c|}{$\begin{array}{l}\text { * Some SD and range values not available. } \\
\mathrm{HRCT}=\text { high-resolution computed tomography } \\
\mathrm{ND}=\text { no data available }\end{array}$} \\
\hline
\end{tabular}

Hydroxychloroquine ${ }^{49,50}$, gold, 51 and corticosteroids ${ }^{52,53}$ are the oldest non-biological DMARDs used in the treatment of RA. Newer agents include methotrexate (MTX), ${ }^{54}$ sulfasalazine, ${ }^{55}$ and leflunomide. ${ }^{56}$ Doran et al found that use of corticosteroids in RA was associated with an increased infections risk: hazard ratio 1.56 , 95\% CI 1.222.01.57 Similar findings came from a small study by Saag et al: odds ratio $8.0,95 \%$ CI $1.0-64.0 .58$ In a large Canadian cohort study (27,710 patients), the authors investigated the prevalence of infections in patients with RA prescribed DMARDs with or without corticosteroids. It was found that 4,941 patients $(18 \%)$ had at least one serious infection (requiring or complicating hospitalization). Interestingly, the use of DMARDs without corticosteroids was not associated with increased serious infection risk (adjusted risk ratio 0.92, 95\% CI 0.85-1.0). In contrast, patients who were prescribed corticosteroids alone (adjusted risk ratio $1.9,95 \%$ CI 1.75-2.05) or with DMARDs (adjusted risk ratio 1.63, 95\% CI 1.5-1.77) had significantly increased risk of serious infections. ${ }^{59}$

Jenks et al found that an incidence of severe infections associated with a use of leflunomide in RA was 3.30/100 patient-years (95\% CI 1.65-5.90). Eleven patients (11/171) developed infection requiring hospitalization, including 3 episodes of lower-respiratory-tract infection. Of note, the patients at increased risk were those with severe disease and taking concomitant MTX and corticosteroids. ${ }^{60}$

MTX is the most used conventional DMARD. Its influence, as well as that of azathioprine, on the prevalence of infection in RA was studied by Boerbooms et al. During 4 years of follow-up the prevalence of infections was $18 \%$ in the MTX open study group, and 7\% in the MTX and azathioprine groups in a 12-month double blind randomized trial, which was followed by 3 years open extension.
There was a trend for more infections to occur early in the treatment period (within 1.5 years) and with more severe RA. ${ }^{61}$ Using the Registry of Japanese Rheumatoid Arthritis Patients on Biologics for Long-term Safety (REAL) data was shown that treatment with high- or low-dose MTX was not associated with an increased risk of serious infection, when compared with the non-MTX group (use of corticosteroids across groups was similar). ${ }^{62}$ There is also no evidence that sulfasalazine is associated with an increased risk of serious infections, as reported in several randomized controlled trials. ${ }^{63-65}$

Biological DMARDs approved for RA can be divided into 3 groups: tumor necrosis factor inhibitors (adalimumab, etanercept, and infliximab); anti-CD 20 therapy (rituximab); and $\mathrm{T}$ cell costimulator modulators (abatacept). ${ }^{66}$ The long-term safety profile of the above agents has been evaluated in a large number of patients with RA. Rituximab was studied in population of 3,189 patients. The overall rate for serious infections was reported as 4.35 events/100 patient-years, similar to that observed in the placebo group. Lower respiratory-tract infections were the most frequent, with pneumonia accounting for $2 \%$ of all infections. ${ }^{67}$ Safety profile studies of adalimumab $(2,300$ patients), etanercept (2,385 patients), and abatacept showed that these drugs, when compared against placebo, did not increase the risk of infection in RA patients. ${ }^{68-70}$ In contrast, infliximab was associated with an increased risk of infection when used in RA. In a group of 504 RA patients, infections accounted for the highest number of adverse events (1.6\%). When the infectious agent was recognized, the most common type was non-tuberculosis-type bacteria $(n=38)$, with tuberculosis accounting for 4 cases. ${ }^{71}$ Overall there is an increased absolute $0.2 \%$ a year risk of re- 
activation of tuberculosis in the RA subjects treated with biological agents. ${ }^{72}$

Publications reporting direct effect of biological DMARDs on the course of the RA-BR are unfortunately scarce. In a small retrospective study (42 patients with RA-BR), the authors showed that the use of the biological agents, when compared against non-biological DMARD treatment, resulted in an increased infections rate (odds ratio 8.7). ${ }^{73}$

\section{Management}

BR and RA are both chronic conditions requiring longterm medical management. Specific guidelines for management of patients with concurrent RA-BR are lacking, and the evidence base to formulate such recommendations is limited. At present we would suggest that the management of such patients should be broadly based on the guidelines in place for the separate conditions $s^{8,74}$ but influenced by the literature summarized above, by the knowledge of the adverse prognostic data, and by clinical experience.

We propose that all patients with RA-BR should undergo review by a specialist chest physician with an interest in BR, who should liaise closely with the responsible rheumatologist. Screening for other causes of BR, in particular for immune deficiency (which may occur secondary to treatment for RA), should be carried out. For patients with asymptomatic chest disease and quiescent RA, annual review would seem sufficient. Patients with sputum production should be reviewed by a respiratory physiotherapist for instruction in airway clearance, and mucolytics may be of value. Patients with active inflammatory joint disease or symptomatic pulmonary disease are at risk of more advanced/progressive respiratory problems and should be offered regular monitoring, 3-6-monthly, with clinical, lung function test, screening for bacterial colonization by sputum culture, and radiological assessment. A trial of inhaled corticosteroids may be appropriate for those with reversible airways obstruction. All patients, especially prior to commencement of immunosuppression, should be offered vaccination against pneumococcal and influenza infection. Strict follow-up should be offered to patients with RA on biological and non-biological DMARDs, so treatment can be stopped or changed when serious adverse events occur.

Corticosteroids and some DMARDs increase the risk of infections, as documented above, and may have other effects on the lungs (such as pneumonitis of fibrotic reactions). The choice of DMARD should be made with the pulmonary disease taken into consideration, and preferably after consultation between rheumatology and respiratory specialists. For patients commencing therapy with anti-tumor necrosis factor agents, careful screening for non-tuberculous mycobacteria seems appropriate; these agents should not be used in patients with RA-BR colo- nized with non-tuberculous mycobacteria or with active mycobacterial infection. For those patients with moderate to severe BR or frequent exacerbations it would seem reasonable to select DMARDs with a lower propensity to worsen pulmonary infection, at least in the first instance. Prompt assessment and treatment with appropriate oral or intravenous antibiotics should always be readily available.

Antibiotic prophylaxis should be considered in patients with frequent ( 3 or more exacerbations per year) or severe infections requiring hospitalization/intravenous antibiotics, and the choice of agent should be guided by sputum microbiology, as documented in the British Thoracic Society bronchiectasis guidelines. ${ }^{74}$

For patients with severe or progressive disease, or those who do not respond to first line treatment options, review by a multidisciplinary team for patients with RA-BR, including a radiologist, chest physician, rheumatologist, specialist nurse, and physiotherapist, could be utilized to draw up and implement an individualized long-term management plan.

Smoking cessation advice is appropriate, despite the lack of evidence that smoking contributes to the development of bronchiectasis in this setting. We also advocate for patients with RA-BR with a reduced exercise tolerance and low health related quality of life enrolling in pulmonary rehabilitation programs. There is accumulating evidence that patients with BR who complete out-patient pulmonary rehabilitation achieve an improvement in exercise capacity and health related quality of life. Benefits were shown to be maintained for up to 12 months post pulmonary rehabilitation completion, similar to the COPD group..$^{40}$

\section{Summary}

In early studies demonstrating an association between the 2 conditions, BR was found to precede RA by a mean of 16.4-28.6 years. ${ }^{9,12-14,18}$ In addition, the mean age at the onset of RA in the group with BR $(46.1 \pm 14.0 \mathrm{y})$ was significantly lower than in the group without BR $\left(51.2 \pm 11.4\right.$ y). ${ }^{75}$ Some authors have hypothesized that chronic infection as a result of BR provided a prolonged source of antigenic stimulation that, in genetically predisposed individuals, led to development of RA. ${ }^{14}$ However, the detection of BR in up to $50 \%$ of unselected patients with RA (most of whom have no respiratory symptoms) argues against this hypothesis, and suggests that RA is an independent risk factor for BR development. The mechanism(s) underlying the association of these conditions remain unclear, although immunological process and perhaps genetic predisposition seem to be implicated. Further research is needed in this area.

HRCT should be used in the diagnostic algorithm, especially since RA patients can have pulmonary involvement without clinical symptoms or signs of lung disease. 


\section{Coexistence of Bronchiectasis and Rheumatoid Arthritis: Revisited}

The clinical implications for such asymptomatic patients are unclear. In symptomatic patients, concomitant RA-BR disease is associated with increased risk of infections and higher mortality, with shortened life expectancy. RA-BR patients require regular follow-up, with the involvement of a multidisciplinary team, including a chest physician, prompt treatment of infections, and recognition of adverse effects secondary to immunosuppressive treatment.

\section{REFERENCES}

1. Alamanos Y, Voulgari PV, Drosos AA. Incidence and prevalence of rheumatoid arthritis, based on the 1987 American College of Rheumatology criteria: a systematic review. Semin Arthritis Rheum 2006; 36(3):182-188.

2. Roschmann RA, Rothenberg RJ. Pulmonary fibrosis in rheumatoid arthritis: a review of clinical features and therapy. Semin Arthritis Rheum 1987;16(3):174-185.

3. Amital A, Shitrit D, Adir Y. The lung in rheumatoid arthritis. Presse Med 2011;40(1 Pt 2):e31-e48.

4. Aronoff A, Bywaters EG, Fearnley GR. Lung lesions in rheumatoid arthritis. Br Med J 1955;2(4933):228-232.

5. Weycker D, Edelsberg J, Oster G, Tino G. Prevalence and economic burden of bronchiectasis. Clin Pulm Med 2005;12(4):205-209.

6. Seitz AE, Olivier KN, Adjemian J, Holland SM, Prevots DR. Trends in bronchiectasis among Medicare beneficiaries in the United States, 2000-2007. Chest 2012;142(2):432-439.

7. Allain J, Saraux A, Guedes C, Valls I, Devauchelle V, Le Goff P. Prevalence of symptomatic bronchiectasis in patients with rheumatoid arthritis. Rev Rhum Engl Ed 1997;64(10):531-537.

8. Luqmani R, Hennell S, Estrach C, Basher D, Birrell F, Bosworth A, et al; British Society for Rheumatology; British Health Professionals in Rheumatology. Guideline for the management of rheumatoid arthritis (after the first 2 years). Rheumatology (Oxford) 2009;48(4): 436-439.

9. Solanki T, Neville E. Bronchiectasis and rheumatoid disease: is there an association? Br J Rheumatol 1992;31(10):691-693.

10. Pasteur MC, Helliwell SM, Houghton SJ, Webb SC, Foweraker JE, Coulden RA, et al. An investigation into causative factors in patients with bronchiectasis. Am J Respir Crit Care Med 2000;162(4 Pt 1): 1277-1284

11. McShane PJ, Naureckas ET, Strek ME. Bronchiectasis in a diverse US population: effects of ethnicity on etiology and sputum culture. Chest 2012;142(1):159-167.

12. Bamji A, Cooke N. Rheumatoid arthritis and chronic bronchial suppuration. Scand J Rheumatol 1985;14(1):15-21.

13. Shadick NA, Fanta CH, Weinblatt ME, O'Donnell W, Coblyn JS. Bronchiectasis. A late feature of severe rheumatoid arthritis. Medicine (Baltimore) 1994;73(3):161-170.

14. Walker WC, Wright V. Pulmonary lesions and rheumatoid arthritis. Medicine (Baltimore) 1968;47(6):501-520.

15. Cortet B, Perez T, Roux N, Flipo RM, Duquesnoy B, Delcambre B, et al. Pulmonary function tests and high resolution computed tomography of the lungs in patients with rheumatoid arthritis. Ann Rheum Dis 1997;56(10):596-600.

16. Metafratzi ZM, Georgiadis AN, Ioannidou CV, Alamanos Y, Vassiliou MP, Zikou AK, et al. Pulmonary involvement in patients with early rheumatoid arthritis. Scand J Rheumatol 2007;36(5):338-344.

17. Demoruelle MK, Weisman MH, Simonian PL, Lynch DA, Sachs PB, Pedraza IF, et al. Brief report: airways abnormalities and rheumatoid arthritis-related autoantibodies in subjects without arthritis: early injury or initiating site of autoimmunity? Arthritis Rheum 2012;64(6): 1756-1761.
18. McMahon MJ, Swinson DR, Shettar S, Wolstenholme R, Chattopadhyay C, Smith P, et al. Bronchiectasis and rheumatoid arthritis: a clinical study. Ann Rheum Dis 1993;52(11):776-779.

19. Snowden N, Moran A, Booth J, Haeney MR, Swinson DR. Defective antibody production in patients with rheumatoid arthritis and bronchiectasis. Clinical rheumatology 1999;18(2):132-135.

20. Casals T, De-Gracia J, Gallego M, Dorca J, Rodriguez-Sanchon B, Ramos MD, et al. Bronchiectasis in adult patients: an expression of heterozygosity for CFTR gene mutations? Clin Genet 2004;65(6): 490-495.

21. Puechal X, Fajac I, Bienvenu T, Desmazes-Dufeu N, Hubert D, Kaplan JC, et al. Increased frequency of cystic fibrosis $\Delta$ F508 mutation in bronchiectasis associated with rheumatoid arthritis. Eur Respir J 1999;13(6):1281-1287.

22. Puechal X, Bienvenu T, Genin E, Berthelot JM, Sibilia J, Gaudin P, et al. Mutations of the cystic fibrosis gene in patients with bronchiectasis associated with rheumatoid arthritis. Ann Rheum Dis 2011; 70(4):653-659.

23. Hillarby MC, McMahon MJ, Grennan DM, Cooper RG, Clarkson RW, Davies EJ, et al. HLA associations in subjects with rheumatoid arthritis and bronchiectasis but not with other pulmonary complications of rheumatoid disease. Br J Rheumatol 1993;32(9):794-797.

24. Bilgici A, Ulusoy H, Kuru O, Celenk C, Unsal M, Danaci M. Pulmonary involvement in rheumatoid arthritis. Rheumatol Int 2005; 25(6):429-435.

25. Kallberg H, Ding B, Padyukov L, Bengtsson C, Ronnelid J, Klareskog L, et al. Smoking is a major preventable risk factor for rheumatoid arthritis: estimations of risks after various exposures to cigarette smoke. Ann Rheum Dis 2011;70(3):508-511.

26. Sugiyama D, Nishimura K, Tamaki K, Tsuji G, Nakazawa T, Morinobu A, et al. Impact of smoking as a risk factor for developing rheumatoid arthritis: a meta-analysis of observational studies. Ann Rheum Dis 2010;69(1):70-81.

27. Kaushik VV, Hutchinson D, Desmond J, Lynch MP, Dawson JK. Association between bronchiectasis and smoking in patients with rheumatoid arthritis. Ann Rheum Dis 2004;63(8):1001-1002.

28. Remy-Jardin M, Remy J, Cortet B, Mauri F, Delcambre B. Lung changes in rheumatoid arthritis: CT findings. Radiology 1994;193(2): 375-382.

29. Au K, Reed G, Curtis JR, Kremer JM, Greenberg JD, Strand V, et al. High disease activity is associated with an increased risk of infection in patients with rheumatoid arthritis. Ann Rheum Dis 2011;70(5): 785-791.

30. Geri G, Dadoun S, Bui T, Del Castillo Pinol N, Paternotte S, Dougados $\mathrm{M}$, et al. Risk of infections in bronchiectasis during diseasemodifying treatment and biologics for rheumatic diseases. BMC Infect Dis 2011;(11):304.

31. Perez T, Remy-Jardin M, Cortet B. Airways involvement in rheumatoid arthritis: clinical, functional, and HRCT findings. Am J Respir Crit Care Med 1998;157(5 Pt 1):1658-1665.

32. Mori S, Koga Y, Sugimoto M. Small airway obstruction in patients with rheumatoid arthritis. Mod Rheumatol 2011;21(2):164-173.

33. Tanaka N, Kim JS, Newell JD, Brown KK, Cool CD, Meehan R, et al. Rheumatoid arthritis-related lung diseases: CT findings. Radiology 2004;232(1):81-91.

34. Terasaki H, Fujimoto K, Hayabuchi N, Ogoh Y, Fukuda T, Muller NL. Respiratory symptoms in rheumatoid arthritis: relation between high resolution CT findings and functional impairment. Radiat Med 2004;22(3):179-185.

35. Goeminne PC, Verschueren P, Scheers H, Dupont LJ. Safety of immunomodulatory therapy in patients with bronchiectasis associated with rheumatic disease and IBD: a retrospective and cohort analysis. Clin Rheumatol 2012;31(2):367-373. 


\section{Coexistence of Bronchiectasis and Rheumatoid Arthritis: Revisited}

36. McDonagh J, Greaves M, Wright AR, Heycock C, Owen JP, Kelly C. High resolution computed tomography of the lungs in patients with rheumatoid arthritis and interstitial lung disease. Br J Rheumatol 1994;33(2):118-122.

37. Hassan WU, Keaney NP, Holland CD, Kelly CA. High resolution computed tomography of the lung in lifelong non-smoking patients with rheumatoid arthritis. Ann Rheum Dis 1995;54(4):308-310.

38. Hounsfield GN. Picture quality of computed tomography. AJR Am J Roentgenol 1976;127(1):3-9.

39. Arnett FC, Edworthy SM, Bloch DA, McShane DJ, Fries JF, Cooper NS, et al. The American Rheumatism Association 1987 revised criteria for the classification of rheumatoid arthritis. Arthritis Rheum 1988;31(3):315-324.

40. Cortet B, Flipo RM, Remy-Jardin M, Coquerelle P, Duquesnoy B, Remy J, et al. Use of high resolution computed tomography of the lungs in patients with rheumatoid arthritis. Ann Rheum Dis 1995; 54(10):815-819

41. Zou YQ, Li YS, Ding XN, Ying ZH. The clinical significance of HRCT in evaluation of patients with rheumatoid arthritis-associated interstitial lung disease: a report from China. Rheumatol Int 2012; 32(3):669-673.

42. Zrour SH, Touzi M, Bejia I, Golli M, Rouatbi N, Sakly N, et al. Correlations between high-resolution computed tomography of the chest and clinical function in patients with rheumatoid arthritis. Prospective study in 75 patients. Joint Bone Spine 2005;72(1):41-47.

43. Mohd Noor N, Mohd Shahrir MS, Shahid MS, Abdul Manap R, Shahizon Azura AM, Azhar Shah S. Clinical and high resolution computed tomography characteristics of patients with rheumatoid arthritis lung disease. Int J Rheum Dis 2009;12(2):136-144.

44. Demir R, Bodur H, Tokoglu F, Olcay I, Ucan H, Borman P. High resolution computed tomography of the lungs in patients with rheumatoid arthritis. Rheumatol Int 1999;19(1-2):19-22.

45. Izumiyama T, Hama H, Miura M. Frequency of broncho-bronchiolar disease in rheumatoid arthritis: an examination by high resolution computed tomography. Mod Rheumatol 2002;12(4):311-317.

46. Despaux J, Manzoni P, Toussirot E, Augé B, Cedoz JP, Wendling D. Prospective study of the prevalence of bronchiectasis in rheumatoid arthritis using high-resolution computed tomography. Rev Rhum Engl Ed 1998;65(7-9):453-461.

47. Ong HK, Lee AL, Hill CJ, Holland AE, Denehy L. Effects of pulmonary rehabilitation in bronchiectasis: a retrospective study. Chron Respir Dis 2011;8(1):21-30.

48. Swinson DR, Symmons D, Suresh U, Jones M, Booth J. Decreased survival in patients with co-existent rheumatoid arthritis and bronchiectasis. Br J Rheumatol 1997;36(6):689-691.

49. Scull E. Chloroquine and hydroxychloroquine therapy in rheumatoid arthritis. Arthritis Rheum 1962;5:30-36.

50. Kersley GD, Palin AG. Amodiaquine and hydroxychloroquine in rheumatoid arthritis. Lancet 1959;2(7108):886-888

51. Ellman P, Lawrence JS, Thorold GP. Gold therapy in rheumatoid arthritis. Br Med J 1940;2(4157):314-316.

52. Batterman RC, Hagemann PO. Treatment of rheumatoid arthritis: salicylates, corticosteroids. Postgrad Med 1959;25(1):96-101.

53. Williams GT. A comparative evaluation of newer corticosteroids in the treatment of rheumatoid arthritis. South Med J 1959;52(3):267-273.

54. Pincus T, Yazici Y, Sokka T, Aletaha D, Smolen JS. Methotrexate as the "anchor drug" for the treatment of early rheumatoid arthritis. Clin Exp Rheumatol 2003;21(5 Suppl 31):S179-S185.

55. Pinals RS. History of enteric coated sulfasalazine in rheumatoid arthritis. J Rheumatol Suppl 1988;16:1-4.

56. Herrmann ML, Schleyerbach R, Kirschbaum BJ. Leflunomide: an immunomodulatory drug for the treatment of rheumatoid arthritis and other autoimmune diseases. Immunopharmacology 2000;47(2-3): 273-289.
57. Doran MF, Crowson CS, Pond GR, O'Fallon WM, Gabriel SE Predictors of infection in rheumatoid arthritis. Arthritis Rheum 2002; 46(9):2294-2300

58. Saag KG, Koehnke R, Caldwell JR, Brasington R, Burmeister LF, Zimmerman B, et al. Low dose long-term corticosteroid therapy in rheumatoid arthritis: an analysis of serious adverse events. Am J Med 1994;96(2):115-123.

59. Lacaille D, Guh DP, Abrahamowicz M, Anis AH, Esdaile JM. Use of nonbiologic disease-modifying antirheumatic drugs and risk of infection in patients with rheumatoid arthritis. Arthritis Rheum 2008; 59(8):1074-1081.

60. Jenks KA, Stamp LK, O'Donnell JL, Savage RL, Chapman PT. Leflunomide-associated infections in rheumatoid arthritis. J Rheumatol 2007;34(11):2201-2203.

61. Boerbooms AMT, Kerstens PJSM, van Loenhout JWA, Mulder J, van de Putte LBA. Infections during low-dose methotrexate treatment in rheumatoid arthritis. Semin Arthritis Rheum 1995;24(6):411-421.

62. Sakai R, Komano Y, Tanaka M, Nanki T, Koike R, Nakajima A, et al. The REAL database reveals no significant risk of serious infection during treatment with a methotrexate dose of more than $8 \mathrm{mg} /$ week in patients with rheumatoid arthritis. Mod Rheumatol 2011; 21(4):444-448

62. The Australian Multicentre Clinical Trial Group. Sulfasalazine in early rheumatoid arthritis. J Rheumatol 1992;19(11):1672-1677.

64. Chalmers IM, Sitar DS, Hunter T. A one-year, open, prospective study of sulfasalazine in the treatment of rheumatoid arthritis: adverse reactions and clinical response in relation to laboratory variables, drug and metabolite serum levels, and acetylator status. J Rheumatol 1990;17(6):764-770.

65. Rains CP, Noble S, Faulds D. Sulfasalazine. A review of its pharmacological properties and therapeutic efficacy in the treatment of rheumatoid arthritis. Drugs 1995;50(1):137-156.

66. Malottki K, Barton P, Tsourapas A, Uthman AO, Liu Z, Routh K, et al. Adalimumab, etanercept, infiximab, rituximab and abatacept for the treatment of rheumatoid arthritis after the failure of a TNF inhibitor. Health Technol Assess 2011;15(14):1-278.

67. van Vollenhoven R, Emery P, Bingham CO3rd, Keystone EC, Fleischmann R, Furst DE, et al. Long-term safety of patients receiving rituximab in rheumatoid arthritis clinical trials. J Rheumatol 2010; 37(3):558-567. Erratum in: J Rheumatol 2010;37(10):2198.

68. Genovese MC, Becker JC, Schiff M, Luggen M, Sherrer Y, Kremer J, et al. Abatacept for rheumatoid arthritis refractory to tumor necrosis factor alpha inhibition. N Engl J Med 2005;353(11):1114-1123.

69. Wiens A, Correr CJ, Venson R, Otuki MF, Pontarolo R. A systematic review and meta-analysis of the efficacy and safety of adalimumab for treating rheumatoid arthritis. Rheumatol Int 2010;30(8): 1063-1070.

70. Wiens A, Correr CJ, Pontarolo R, Venson R, Quinalha JV, Otuki MF. A systematic review and meta-analysis of the efficacy and safety of etanercept for treating rheumatoid arthritis. Scand J Immunol 2009;70(4):337-344

71. Delabaye I, De Keyser F. 74-week follow-up of safety of infliximab in patients with refractory rheumatoid arthritis. Arthritis Res Ther 2010;12(3):R121

72. Tugwell P, Singh JA, Wells GA. Biologicals for rheumatoid arthritis BMJ 2011;343:d4027.

73. Geri G, Dadoun S, Paternotte S. The infectious risk of the lower respiratory tract is increased in patients with rheumatic diseases treated by biologic DMARDs, in particular in case of pre-existing colonisation. Arthritis Rheum 2010;62(Suppl): 1648 .

74. Pasteur MC, Bilton D, Hill AT. British Thoracic Society guideline for non-CF bronchiectasis. Thorax 2010;65(7):577.

75. McMahon MJ, Swinson DR. Younger onset of rheumatoid arthritis in patients with bronchiectasis. Br J Rheumatol 1993;32(Suppl):125. 